\title{
SUSTENTABILIDADE EMPRESARIAL: UM ENFOQUE NA GESTÃO CONTEMPORÂNEA
}

\section{BUSINESS SUSTAINABILITY: A FOCUS ON CONTEMPORARY MANAGEMENT}

Danilo Carvalho Miranda

\begin{abstract}
Especialista em Gestão de Negócios e Finanças; Graduado em Administração; Professor dos Cursos de Administração e Engenharia Civil na Faculdade Presidente Antonio Carlos de

Teófilo Otoni/MG - Email: danilocarvalho.unipacto@hotmail.com
\end{abstract}

\section{Resumo}

O mundo vive em constantes mudanças decorrentes de diversos fatores, principalmente os relacionados à maneira em que o homem se posiciona junto ao ecossistema. No que diz respeito aos empreendimentos e às estratégias de negócios não é diferente, a abrangência do tema sustentabilidade empresarial na gestão contemporânea representa a ênfase que os negócios modernos exigem em sua essência. Através do presente artigo, a evolução do pensamento sustentável e sua importância serão retratadas sob uma pesquisa bibliográfica bem alicerçada e disseminada até a atualidade. Perpassando pela essência da sustentabilidade empresarial e sua importância na contemporaneidade.

Palavras-chave: Mundo; sustentabilidade empresarial; negócios; contemporaneidade.

\section{Abstract}

The world lives in constantly changes, resulting from a number of factors, especially those that are in the way positions are held in the ecosystem. As far as entrepreneurship and business strategies are concerned, the division of business sustainability in contemporary management represents the emphasis that modern companies demand at their core. Through this article, the evolution of sustainable thinking and its importance will be portrayed under a well-founded and widespread bibliographic research to date. Passing through the essence of corporate sustainability and its importance in contemporary times.

Keywords: World; corporatesustainability; Business; contemporaneity.

\section{Introdução}

O tema sustentabilidade e negócios consiste em parte integrante da evolução dos empreendimentos e atualmente figura como premissa para o sucesso. Durante 
séculos as questões ambientais já eram discutidas mundialmente, mas as perspectivas de negócios através da sustentabilidade só se acentuariam com a intensificação do comércio e a concorrência mercadológica. A então preocupação com a exploração e produção em massa abriria espaço para as novas estratégias ligadas à sustentabilidade, e às preocupações com o bem-estar social e ambiental.

Atualmente, os temas sustentabilidade e responsabilidade ambiental vêm sendo parte do planejamento estratégico das organizações. Há, portanto, uma maior demanda em atender o compromisso social e ambiental assistido por reivindicações modernas às práticas conscientes. Assim sendo, as empresas contemporâneas seguem os rumos das precursoras organizações e se predispõem a direcionar seus investimentos às ações que busquem atender não só aos interesses econômicos, mas àqueles que perpetuam a imagem de responsabilidade socioambiental, e por consequência, gerem rentabilidade sob novas práticas de gestão economicamente viáveis.

O desenvolvimento do trabalho é a oportunidade de contribuir para a evolução das novas teorias de gestão, e além do mais é a contribuição mínima que o empreendedor pode exercer com sua fonte primária dos negócios e a sociedade. Sua divulgação certamente representará um incentivo extra para novas descobertas em um tema de crescente visibilidade, alcançando os objetivos propostos e avançando sob novas ideias de pesquisa.

Desta forma, este artigo levantará como questionamento de pesquisa: Qual importância da Sustentabilidade Empresarial na Gestão Contemporânea? E como objetivos, buscará identificara essência da Sustentabilidade ao longo dos tempos e compreender a importância da Sustentabilidade Empresarial na atualidade, observando através de uma pesquisa bibliográfica fundamentada o universo que se situa $o$ assunto.

\section{0 ambiente da Sustentabilidade Empresarial}

Na sua essência, a palavra sustentabilidade provém do Latim "sustentare" e remete à manutenção ou capacidade de preservar algo por um tempo. No âmbito empresarial e social a Sustentabilidade sempre foi definida a partir de diversas abordagens e múltiplos princípios, todos estes voltados para a composição dos cenários em que se encontravam e - principalmente -o futuro da humanidade. 
Há muitos anos a sociedade já sinalizava a preocupação ambiental, porém o ecossistema vasto e rico, visto como inesgotável, representava apenas a ideia de matéria prima para os negócios. A partir da Revolução Industrial, segundo Barbiere (2004), há um aumento significativo de bens e materiais que passariam a afetar o ecossistema em decorrência da produção em massa. Para o autor, as proporções seriam tão vultuosas que 0 próprio planeta apresentaria dificuldades em acondicionar a larga escala de produtos impactantes, ou não, ao meio ambiente.Portanto, esta afirmativa veraz já soava paralelamente a um crescimento demográfico cada vez mais evidente.

Historicamente em 1968, o Clube de Roma, formado por cientistas, economistas e representantes da sociedade e indústrias começou a discutir questões decorrentes da exploração desordenada, onde levantou-se questões ligadas às desigualdades sociais, crescimento urbano descontrolado e impactos sobre a exploração desenfreada e impensada (KRÜGER, 2001). As preocupações naquela época, repercutiram como uma utopia surrealista, no entanto motivaram a quebra de paradigmas impostos pelo pensamento capitalista e o Estado.

Neste mesmo sentido, as primeiras aspirações por qualidade de vida e as contestações das formas de gestão empresarial foram questionadas:

\footnotetext{
Uma nova geração desafiava abertamente os pressupostos básicos dos estilos de vida, o complexo militar-industrial, a intervenção militar no estrangeiro, a exploração do meio ambiente, os direitos e os papéis da mulher, os direitos civis, a equidade e a pobreza. (Korten, 1996)

[...] se por um lado os sistemas industriais alcançaram apogeus de sucesso, o capital natural, do qual depende a prosperidade econômica da civilização, declinou rapidamente, sendo que o índice de perdas cresceu na mesma proporção dos ganhos em termos de bem-estar [...] (Hawken, Lovins e Lovins, 2007).
}

Posteriormente, os mesmos levantamentos foram debatidos na I Conferência das Nações Unidas para o Desenvolvimento Humano, realizada em Estocolmo, na Suécia, no ano de 1972 - onde o delineamento do conceito de sustentabilidade deu seus primeiros passos; e na Comissão Mundial sobre o Meio Ambiente e Desenvolvimento - CMMAD, ou Comissão de Burtland, em 1983, com a proposição de crescimento consciente e a conciliação entre questões sociais e ambientais. Ao final o saldo foi altamente positivo sob a concordância da evolução permeada pela sustentabilidade. 
Um fato relevante é que mesmo os dois eventos acontecendo em épocas distintas, ambos ficaram marcados por interesses políticos e conflitos decorrentes do processo de mudanças. $\mathrm{O}$ debate ao longo dos anos foi altamente positivo sob 0 consenso da evolução permeada pela sustentabilidade. Dentre seus vários pontos positivos, harmonizou-se o desenvolvimento econômico consciente como requisito para a melhoria da qualidade de vida.

$\mathrm{Na}$ sua essência, o desenvolvimento sustentável é um processo de mudança no qual a exploração dos recursos, o direcionamento dos investimentos, a orientação do desenvolvimento tecnológico e a mudança institucional estão em harmonia e reforçam o atual e futuro potencial para satisfazer as aspirações e necessidades humanas - do Relatório Brundtland, Nosso Futuro Comum. (CMMAD/83, pag. 41)

Chegamos a um ponto na História em que devemos moldar nossas ações em todo o mundo, com maior atenção para às consequências ambientais. Através da ignorância ou da indiferença podemos causar danos maciços e irreversíveis ao meio ambiente, do qual nossa vida e bem-estar dependem. Por outro lado, através do maior conhecimento e de ações mais sábias, podemos conquistar uma vida melhor para nós e para a posteridade, com um meio ambiente em sintonia com as necessidades e esperanças humanas... (Trechos da Declaração da Conferência da ONU sobre o Meio Ambiente - parágrafo 6)

Segundo os autores Araújo e Mendoça (2009) a expansão econômica do pósSegunda Guerra Mundial (1945 até 1970) vinha gerando significativos desequilíbrios sociais, e o conceito de desenvolvimento sustentável instituído em Estocolmo, surge como uma forma de equilibrar as atividades essenciais à prosperidade social. Para Bellen (2005), o conceito vem de um processo longo, contínuo e complexo de reavaliação crítica da relação existente entre a sociedade civil e seu meio natural, assumindo diversas abordagens e concepções direcionadas ao progresso empresarial e à qualidade de vida.

No Brasil, a Conferência das Nações Unidas para o Meio Ambiente e Desenvolvimento (ECO-92), realizada no Rio de Janeiro, em 1992, marcou a priori as questões climáticas e o consumo humano desordenado. Tal evento trouxe um sábio pensamento: "A tribulação produz a perseverança, a perseverança é uma virtude comprovada, leva à esperança e a esperança não decepciona", correspondendo aos anseios socioambientais não esgotados e emergentes. Este foi considerado como marco global das discussões sobre o assunto, pois teve a participação de representantes governamentais de todo o mundo; seus principais resultados foram dois grandes documentos: A Carta da Terra (rebatizada de Declaração do Rio) e a Agenda 21. 
A Agenda 21 dedica-se aos problemas da atualidade e almeja preparar o mundo para os desafios do século XXI. Ela reflete o consenso global e compromisso político em seu mais alto nível, objetivando o desenvolvimento e o compromisso ambiental. A Declaração do Rio visa estabelecer acordos internacionais que respeitem os interesses de todos e proteja a integridade do sistema global de ecologia e desenvolvimento. (ECO-92)

Ainda no Rio de Janeiro, durante as décadas subsequentes aconteceram encontros com interesses afins, a Rio+10 e Rio+20 (em 2002 e 2012 respectivamente) também abordaram interesses parecidos. Para Costa e Carvalho (2005) contudo, ainda foi na década de 90 que houve o significativo aumento no número de empresas em busca de uma melhoria de imagem através de investimentos em ações sociais;buscando compreender assim, o sentido do modelo de gestão de negócios baseados na Responsabilidade Social Empresarial.

Nesse sentido, Alessio (2008) completou quando disse que a responsabilidade social empresarial é a atuação social da empresa, e ela perpassa por todos os níveis organizacionais, da estratégia até a operação. Segundo o autor, ela procura dar a empresa um caráter mais humano e altruísta, com interesses maiores, e adotando-se esta nova forma de pensar e agir, a organização estará buscando dar a sua contribuição para a sociedade. O que mais uma vez rompeu com o paradigma da exploração em massa de décadas anteriores.

\begin{abstract}
Satisfazer as necessidades e as aspirações humanas é o principal objetivo do desenvolvimento. Nos países em desenvolvimento, as necessidades básicas de grande número de pessoas - alimento, roupas, habitação, emprego - não estão sendo atendidas. Além dessas necessidades básicas, as pessoas também aspiram legitimamente a uma melhor qualidade de vida. Para que haja um desenvolvimento sustentável, é preciso que todos tenham atendido as suas necessidades básicas e lhes sejam proporcionadas oportunidades de concretizar suas aspirações a uma vida melhor [...] (PHILIPPI, 2001).
\end{abstract}

A sociedade tornara-se sustentável, ao atender, simultaneamente, aos critérios de relevância social, prudência ecológica e viabilidade econômica, os três pilares do desenvolvimento sustentável (SACHS, 2002).

O autor Almeida (2002) nos apresenta de maneira distinta outras contestações que a sociedade enfrentou perante o tema sustentabilidade - ignorado por seus integrantes:

[...] Acostumado a dividir o universo em compartimentos estanques para poder entendê-lo - fruto de uma visão cartesiana, mecanicista, reducionista, forjada em trezentos anos de Revolução Científica e Industrial -, nos últimos anos do século XX o homem viu-se às voltas com a constatação de 
que a natureza não se deixa apreender completamente pelas ferramentas tradicionais de análise [...]. Para ser compreendida, pede um novo: orgânico, holístico, integrador [...].

Para Kotler (1997), sustentabilidade do ponto de vista empresarial, significou naquele contexto, possibilitar o sucesso dos negócios em longo prazo e ao mesmo tempo contribuir para o desenvolvimento econômico e social da humanidade, um meio ambiente saudável e uma sociedade mais estável. Para o autor, a relevância do tema por parte das organizações ainda viria a ser a grande responsável pela vantagem competitiva capaz de atrair o consumidor moderno.

Essa afirmação condiz com o que acentua Veiga (2010), que com a imersão do novo termo sustentabilidade, novas regras na concorrência capitalista emergiriam, "obrigando as empresas a adquirirem competência para administrar conflitos e demandas sociais de maneira a se manterem cada vez mais competitivas".

Sustentabilidade empresarial significa assegurar o sucesso do negócio em longo prazo e ao mesmo tempo contribuir para o desenvolvimento econômico e social da comunidade, um meio ambiente saudável e uma sociedade estável. A sustentabilidade tem três amplos componentes, geralmente descritos como: as pessoas, o lucro e planeta (INSTITUTO ETHOS, 2010).

Esta definição estava contida em diversos estudos de John Elkington, americano precursor da teoria do Triple BottomLine - ou Tripé da Sustentabilidade (People, planetandprofit - Pessoas, planeta e lucro), responsável por atrelar a esta teoria o objetivo de despertar nos empreendedores contemporâneos a visão sistêmica de negócios não apenas do ponto de vista financeiro, mas sob o viés econômico, ambiental e social, respaldada por políticas públicas que incentivem neste sentido. Em resumo, seria dizer que as três partes sairiam ganhando e consequentemente todos os que compõem o ecossistema.

Diante deste novo panorama, as empresas passam a se reestruturarem para acompanhar esta nova percepção. As pressões sociais e restrições impostas fazem com que as organizações sejam forçadas a buscar formas de reduzir seu impacto ambiental e a melhorar sua imagem ante a sociedade.

A nova questão, portanto, começa a fazer parte do cotidiano das empresas, e isto, muito mais intimamente ligada à visão dos empreendedores do que à disposição e o acesso a recursos financeiros. Segundo Marcovitch (2006), no universo das empresas contemporâneas tem havido uma busca bem-sucedida de inovação e sustentabilidade (em segmento crescente). E estas, emergem para 
desmistificar a inovação como possibilidade real apenas para grandes empresas, além de fazer com que a mudança para a gestão sustentável seja planejada e incorporada às novas estratégias como triunfo competitivo.

\section{Sustentabilidade Empresarial na gestão contemporânea}

A transposição do paradigma da sustentabilidade inclui vencer as dificuldades comuns a todos os empreendedores, porém envolve percorrer caminhos que apenas os voltados ao sucesso e a novas perspectivas conseguirão vencer. A perspicácia administrativa, porém, engloba uma série de fatores extra organizacionais diretamente ligados aos negócios, mas pouco explorados durante a formulação de estratégias. Daí a oportunidade de indagar e examinar o comportamento das organizações na transposição dos "padrões de mercado".

$\mathrm{Na}$ prática, o desafio atual é unir inovação e ferramentas de gestão sustentável em diferentes segmentos. A nova questão pode ser parte do cotidiano das empresas contemporâneas, e isto está muito mais intimamente ligado à visão dos empreendedores do que ao acesso a recursos financeiros. O paradigma da sustentabilidade empresarial, começou a ser quebrado no momento em que a visão sistêmica da organização recebeu em seus alicerces a introdução do novo desenvolvimento sustentável, aquele que sustenta-se na adoção de medidas simples por parte de seus colaboradores e está profundamente ligado aos objetivos organizacionais, sociais e ambientais prescritos na sobrevivência.

O autor Leff (2009), salientou em uma de suas publicações que marcou a transição para a nova visão sustentável a partir de 2010, que a sustentabilidade anuncia o limite da racionalidade econômica, proclamando os valores da vida, da justiça social e do compromisso com as gerações vindouras. Ou seja, as organizações passavam a enxergar através da integração entre rentabilidade e responsabilidade, o viés social e ambiental antes menosprezado.

Como citado anteriormente, a sustentabilidade empresarial apresentou suas abordagens iniciais em diferentes pontos da história organizacional. Embora fosse apenas uma semente de novas ideias advinda da necessidade de sobrevivência entre homem e meio ambiente, sua representatividade no mercado derivou de interesses da cadeia produtiva e da qualidade de vida. Nesse sentido, Lewis (2010) enfatizou: 
[...] o desenvolvimento sustentável pressupõe compatibilizar o crescimento econômico com a realização integral da pessoa, proporcionando-lhe qualidade de vida, em cumprimento ao primado da dignidade humana, o que demanda especial atenção à realização de todos os aspectos que iluminam os direitos civis, políticos, sociais, culturais e ambientais [...]

Com base na relevância do tema segundo o momento atual, devemos ainda evidenciar a importância da gestão sustentável. Segundo Kotler (1997), sustentabilidade empresarial significa assegurar o sucesso do negócio em longo prazo e ao mesmo tempo contribuir para o desenvolvimento econômico e social da comunidade, um meio ambiente saudável e uma sociedade estável.

Outra forma atual e, substancialmente mais pragmática de efetivar a sustentabilidade empresarial é mediante a ecoeficiência. Ser ecoeficiente é oferecer bens e serviços que satisfaçam as necessidades, gerando impactos ecológicos sempre menores e capazes de serem absorvidos pela natureza. Segundo WBCSD (apud, DIAS, 2000, p.130):

[...] São inúmeras as oportunidades de as empresas serem ecoeficientes. Reorientação dos processos, revalorização dos subprodutos e a recolocação nos mercados podem apresentar um novo posicionamento estratégico, uma nova orientação mercadológica e também uma oportunidade para novos negócios.

Neste sentido, a adoção de normas para a gestão sustentável (ISO14000) e o Índice de Sustentabilidade Empresarial da Bovespa (ISE) também exemplificam as preocupações modernas sobre o tema.

Para Hawken. Lovins e Lovins (2007), a atuação empresarial sustentável também encontra espaço e oportunidade para inovar naquilo que, até então, era tratado como um processo exclusivamente gerador de impactos negativos. $\mathrm{Na}$ indústria moderna por exemplo, a eliminação do desperdício leva a uma cadeia de eventos e processos que podem vir a formar a base de uma surpreendente inovação na esfera empresarial. Portanto, sua acessibilidade é comprovada nos alicerces de quaisquer empreendimentos contemporâneos.

$\mathrm{Na}$ atualidade, os fatores que influenciam os investimentos nas questões de sustentabilidade empresarial estão intimamente ligados à visão do gestor moderno. O direcionamento e a quebra de paradigma são pontos cruziais que determinam o olhar contemporâneo, ou seja a maneira como a sustenbabilidade é percebida seja 
dentro ou fora da organização, é a garantia - ou não, do sucesso das atividades relacionadas.

A ampliação de valores de um empreendimento frente a essa nova era, não apoia-se apenas em uma estratégia e sua performance, mas na mudança de comportamento e comprometimento com o meio ao seu redor. Na direção deste pensamento, cada vez mais as organizações estão buscando colaboradores que tenham em seu DNA a consciência de que estão inseridos em um ecossistema interligado, onde o diferencial competitivo e a rentabilidade redundam em beneficios gerais.

A modernidade empresarialdo século XXI passa pela questão ambiental, pela eficiência econômica e pela contribuição social rumo a um futuro melhor, algo que a tempos atrás foi idealizado por aqueles que tinham nas mãos a principal ferramenta para a mudança - a consciência que empresas, meio ambiente e evolução serão a sobrevivência da humanidade.

\section{Metodologia}

Este estudo consistiu em uma pesquisa bibliográfica fundamentada sob a seguinte questão: Qual a Importância da Sustentabilidade Empresarial na Gestão Contemporânea? E mais especificamente, buscou identificar a essência da Sustentabilidade ao longo dos tempos e compreender a importância da Sustentabilidade Empresarial na atualidade. Contém uma pesquisa de revisão bibliográfica que traz em suas faces a abordagem da sustentabilidade empresarial sob diferentes análises, não abstendo-se de levantar pontos de vista sobre o assunto, mas despertando questionamentos e motivando o aprofundamento sobre a temática.

Para elaboração do mesmo, foram utilizadas referências de autores sob uma vasta revisão bibliográfica, além de pesquisas em revistas, periódicos, sites e videoconferências sobre a temática. Como objetivos, buscou entender a essência da Sustentabilidade ao longo dos tempos e compreender a importância da Sustentabilidade Empresarial na atualidade, observando o universo em que se encontra o assunto. 


\section{Considerações Finais}

Esse trabalho teve como premissas aprofundar a análise sobre o tema Sustentabilidade Empresarial e responder de forma objetiva a seguinte pergunta: Qual importância da Sustentabilidade Empresarial na Gestão Contemporânea? Como objetivos, procurou-se identificar a essência da Sustentabilidade ao longo dos tempos e compreender a importância da Sustentabilidade Empresarial na atualidade, não limitando-se a usar apenas concepções nacionais e a dizer que o tema tem sua plenitude circunscrita no presente trabalho. Todavia, respondeu a estes questionamentos no momento em que trouxe à tona as tempestivas investidas do assunto ao longo da história.

Dentro os diversos estudos explorados, a visão de Bellen (2005) transcreve satisfatoriamente o ponto fundamental do trabalho, quando diz que: "o progresso em direção à sustentabilidade é uma escolha da sociedade, das organizações, das comunidades e dos indivíduos, devendo existir um grande envolvimento de todos os segmentos". Isto é, estamos todos inseridos num mundo que é composto por conviç̧ões que nós mesmos formamos, e somos responsáveis direta e indiretamente pelo meio em que vivemos. Para tanto, é seguindo essa lógica que as empresas devem adotar políticas e práticas de sustentabilidade empresarial, procurando a partir de então, incorporar estrategicamente aos negócios as dimensões - econômica, ambiental e social - do desenvolvimento sustentável.

Pensando no sentido que a Sustentabilidade Empresarial irá integrar os projetos organizacionais, de vida, e convivência, pode-se dizer que até se parece com algo surreal. Tornando-se um cenário preocupante, infelizmente. Para tanto, a formação dessa nova visão contemporânea de aproximar as organizações e a sociedade, de modo multiforme, converge a um só objetivo: a reconsideração dos modelos de gestão empresarial, e por que não,do meio de vida de todos os geradores de mudanças.A disseminação da ideia da Sustentabilidade Empresarial deve ser implantada na atualidade, basta que a sociedade seja capaz de perceber.

\section{Referências}

ABNT. NBR 6022: informação e documentação: artigo em publicação periódica científica impressa: apresentação. Rio de Janeiro, 2003. 5 p. 
ALESSIO, Rosemeri; Responsabilidade Social das Empresas no Brasil: Reprodução de postura ou novos rumos? Porto Alegre: EDIPUCRS, 2008.

ALMEIDA, F. O bom negócio da sustentabilidade. Rio de Janeiro: Nova Fronteira, 2002.

ARAÚJO, G. C.; MENDONÇA, P. S. M. Análise do processo de implantação das normas de sustentabilidade empresarial: um estudo de caso em uma agroindústria frigorífica de bovinos. Revista de Administração Mackenzie, São Paulo, v. 10, n. 2, mar./abr., 2009.

BARBIERI, J. C. Gestão ambiental empresarial. São Paulo: Saraiva, 2004.

BELLEN, H.M.V. Indicadores de sustentabilidade: uma análise comparativa. Rio de Janeiro: Editora FGV, 2005.

Costa, A. M., \& Carvalho, J. L. F. Legitimando papéis ou conciliando interesses? A reprodução discursiva da responsabilidade social empresarial. Anais do encontro Nacional da Associação Nacional de Pós Graduação em Administração. DF- Brasília, 2005.

DIAS, Reinaldo. Gestão ambiental: responsabilidade social e sustentabilidade. São Paulo: Atlas, 2006. WORLD BUSINESS COUNCIL FOR SUSTAINABLE DEVELOPMENT (WBCSD). Disponível em http://www.wbcsd.org. Acesso em abril de.2016.

HAWKEN, Paul; LOVINS, Amory; LOVINS, L. Hunter. Capitalismo natural: criando a próxima revolução industrial. São Paulo: Cultrix, 2007.

INSTITUTO ETHOS. Responsabilidade Social. Disponível em: http://www3.ethos.org.br/cedoc/responsabilidade-social-empresarial-esustentabilidade-para-a-gestao-empresarial/\#.VlecXXarTIU. Acesso em 18 nov. 2015.

KORTEN, D. Quando as corporações regem o mundo: consequências da globalização da economia. São Paulo: Futura, 1996.

KOTLER, Philip. Administração de Marketing: análise, planejamento, implementação e controle. 5. Ed. São Paulo: Atlas, 1997.

KRÜGER, Eduardo. Uma abordagem sistêmica da atual crise ambiental. Desenvolvimento e Meio Ambiente. Curitiba, UFPR, 2001. Disponível em: ufpr.br . Acesso em: 15 nov. 2015.

Leff, E. Saber Ambiental: sustentabilidade, racionalidade, complexidade, poder, $7^{\circ}$ Edição. Rio de Janeiro. Editora Vozes, 2009.

LEWIS, S. B. Responsabilidade social e incentivos fiscais na ciência, tecnologia einovação. Scientia luris, Londrina, v. 14, p. 281-302, nov. 2010.

MARCOVITCH, Jacques. Para mudar o futuro: mudanças climáticas, políticas públicas e estratégias empresariais. São Paulo: Editora da Universidade de São Paulo: Saraiva, 2006.

PHILIPPI, Luiz Sérgio. A Construção do Desenvolvimento Sustentável. In.:

LEITE, Ana Lúcia Tostes de Aquino; MININNI-MEDINA, Naná. Educação Ambiental (Curso básicoà distância) Questões Ambientais - Conceitos, História, Problemas e 
Alternativa. 2. ed, v.5. Brasília:Ministério do Meio Ambiente, 2001.

SACHS, Ignacy. Caminhos para o desenvolvimento sustentável. 3. ed. Rio de Janeiro: Garamond, 2002.

VEIGA, J. E. Indicadores de sustentabilidadae. Estudos Avançados, São Paulo, 24, 22 fev. 2010. Disponível em www.scielo.br 